\title{
Um Estudo sobre as Publicações Contábeis sob o Foco da Semiótica
}

\begin{abstract}
Resumo
Este artigo teve por objetivo analisar as contribuições da utilização dos ensinamentos da semiótica na Contabilidade. O desenvolvimento efetivo da semiótica como ciência moderna, cujo objeto é toda forma de linguagem, somente foi reconhecido entre os séculos XVIII e XIX. Desde então, diversos autores dedicaram-se a estudar este tema, utilizando a semiótica como um instrumento de análise de outras ciências. A Contabilidade, vista como uma ciência, é classificada por muitos autores como uma linguagem, e assim pode ser analisada através dos preceitos da semiótica. Este estudo utiliza-se da pesquisa bibliográfica e da análise de conteúdo realizada sobre os artigos publicados a respeito do assunto nos seguintes congressos: Associação Brasileira de Custo, USP de Controladoria e Contabilidade e Encontros da ANPAD. Além deles, também se pesquisou em 22 revistas científicas internacionais de Contabilidade. O estudo conclui que tanto em congressos brasileiros quanto em revistas científicas internacionais tem havido poucas contribuições teóricas e, principalmente, práticas sobre o uso da semiótica na Contabilidade.
\end{abstract}

Palavras-Chave: Contabilidade; Semiótica; Análise do discurso.

\author{
Fernando Batista Fontana \\ Mestre em Ciências Contábeis (UNISINOS), \\ Professor da Universidade do Vale do \\ Rio dos Sinos (UNISINOS). Contato: \\ Av. Unisinos, 950, Bairro Cristo Rei, São \\ Leopoldo, RS, Brasil, CEP: 93022-000. \\ E-mail: fbfontana@unisinos.br
}

\section{Carlos Alberto Diehl}

Doutor em Engenharia de Produção (UFSC/ HEC-Montreal), Professor do Programa de Pós-graduação em Ciências Contábeis da Unisinos. Contato: Av. Unisinos, 950, Bairro Cristo Rei, São Leopoldo, RS, Brasil, CEP: 93022-000.

E-mail:cd@unisinos.br

\section{Marcos Antonio de Souza \\ Doutor em Controladoria e Contabilidade (USP), Professor do Programa de Pós- graduação em Ciências Contábeis da Unisinos. Contato: Av. Unisinos, 950, Bairro Cristo Rei, São Leopoldo, RS, Brasil, CEP: 93022-000. \\ E-mail:marcosas@unisinos.br}

\section{Clea Beatriz Macagnan}

Doutora em Creación, Estratégia e Gestión de Empresas (Universidad Autonoma de Barcelona), Coordenadora do Programa de Pós-graduação em Ciências Contábeis da Unisinos. Contato: Av. Unisinos, 950, Bairro Cristo Rei, São Leopoldo, RS, Brasil, CEP: 93022-000.

E-mail:clea@unisinos.br 


\section{Introdução}

De acordo com Watzlawack, Beavin e Jackson (1971), o primeiro axioma da comunicação afirma que é impossível não se comunicar. Cada pessoa, objeto, força ou organização permanece continuamente comunicando. Essa comunicação ocorre, muitas vezes, involuntariamente, porque ela transcende o limite da escrita ou da fala e pode apresentar-se por meio de outras formas de expressão. Existe um condicionamento histórico que tem levado à impressão de que as únicas formas de conhecimento do mundo são aquelas veiculadas pela língua, na sua manifestação como linguagem verbal, oral e ou escrita (Santaella, 1983). Saussure (2006) sustenta este entendimento ao tratar sobre o prestígio que existe da escrita sobre a fala, sendo uma de suas explicações para esse fenômeno a impressão causada pelas imagens gráficas das palavras, como um objeto sólido e permanente, mais adequado do que o som da fala para constituir a língua através dos tempos.

Todas as coisas comunicam-se de alguma forma, seja pelo som, cor, modo, ou desempenho, estabelecendo um sentido, um significado. A consequência desse fato elementar - que o mundo tenha sentido - é que o comportamento (ou também a ausência de comportamento) de cada pessoa ou organização é uma potencial fonte de comunicação (Volli, 2004). Nesse contexto, os preceitos da semiótica podem ser aplicados e assim contribuir com toda e qualquer ciência, mas, principalmente, com as que utilizam linguagens próprias, como, por exemplo, a Contabilidade. "A semiótica tem dupla relação com as ciências: ela é, simultaneamente, uma ciência entre as ciências e um instrumento das ciências" (Morris, 1976, p. 10).

Nesta perspectiva, este estudo teve por objetivo analisar as contribuições da utilização dos conhecimentos da semiótica na elaboração de estudos científicos em Contabilidade. A relevância está na identificação da lacuna existente de trabalhos que utilizem a teoria ou a prática de semiótica na Contabilidade, tema este bastante relevante devido ao potencial desta ciência como instrumento de auxílio ao avanço de outras ciências.

O artigo inicia com esta introdução, seguida da revisão de literatura sobre o tema semiótica e sua conexão com a Contabilidade. Logo após, é apresentada a metodologia utilizada no estudo. A seguir, são elencados os resultados obtidos da pesquisa e sua interpretação. Para encerrar, o artigo apresenta as considerações finais sobre o assunto e as referências utilizadas para o seu desenvolvimento.

\section{Semiótica e conexão com a Contabilidade}

Este capítulo apresenta uma revisão de literatura sobre Semiótica, com o intuito de entender sua relação com a Contabilidade.

O vocábulo semiótica vem da raiz grega semeîon, que significa signo. Na origem histórica das ciências, é preciso distinguir o desenvolvimento de uma semiótica propriamente dita e as tendências de uma semiótica avant la lettre, ou seja, antes de seu desenvolvimento numa maior completude. A semiótica propriamente dita foi inaugurada por filósofos como John Locke (1632-1704) e Johann Heinrich Lambert (1728-1777). Já a semiótica avant la lettre compreende todas as investigações sobre a natureza dos signos, da significação e da comunicação na história das ciências. Essas investigações tiveram seu início com a origem da filosofia (Nöth, 1995). Essa fase da semiótica avant la lettre esteve presente em reflexões muito antigas, época em que se ocupavam com signos e com a linguagem. Desde os pré-socráticos Platão e Aristóteles, como os Estóicos, Agostinho e a própria Escolástica, além de toda a filosofia moderna, a partir de Descartes (Nöth, 1995; Volli, 2000).

Existe uma dupla relação entre os signos e a ciência. Os signos e a ciência estão inextricavelmente conectados, pois, simultaneamente, a ciência oferece aos homens signos mais confiáveis e expressa seus próprios resultados num sistema de signos (Morris, 1994).

O desenvolvimento efetivo da semiótica, como ciência moderna, somente foi reconhecido entre os séculos XVIII e XIX. Primeiramente abordada pelo linguista Ferdinand de Saussure e pelo filósofo, ma- 
temático e lógico, Charles Sanders Peirce. Dessa forma, a semiótica atual assumiu duas correntes diferentes; (a) a corrente estrutural, decorrente de Saussure; (b) a semiótica interpretativa decorrente do filósofo Peirce. Desde as contribuições desses autores, diversos estudiosos buscaram desenvolver e aprimorar as ideias e conceitos formados, destacando-se dentre eles os trabalhos de: Louis Hjelmslev, Claude Lévi-Strauss, Algirras J. Greimas e Umberto Eco, para citar alguns (Nöth, 1995).

A corrente estrutural abordada por Saussure entende a linguagem pela distinção do social e do individual. Enquanto o social recai na língua, é na fala que se encontra o individual. A língua (linguagem menos a fala) "apresenta-se ao indivíduo como um sistema preexistente, uma instituição social que acumulou historicamente uma série de valores e sobre a qual, em princípio, o indivíduo não tem nenhuma ascendência enquanto indivíduo" (Coelho 1990, p. 18). Portanto, a língua configura-se por um sistema de regras estabelecido por uma dada sociedade, enquanto a fala é um processo que dá existência concreta à língua. Este é um sistema de signos que exprimem ideias, como, por exemplo: a escrita, o alfabeto dos surdos-mudos, os ritos simbólicos, as formas de polidez e os sinais militares. Essa definição de língua coloca essa corrente no campo de estudo da semiótica, já que é formada por um sistema de signos, pertencendo assim a uma linguagem. Esta perspectiva teórica explicita a relação entre a língua e a fala.

Língua e fala: cada um destes dois termos só tira evidentemente sua definição plena do processo dialético que une um ao outro: não há língua sem fala e não há fala fora da língua. (...) A língua e a fala estão, portanto, numa relação de compreensão recíproca; de um lado, a língua sendo a soma coletiva de marcas individuais, só pode ser incompleta no nível de cada indivíduo isolado; a língua existe perfeitamente apenas na 'massa falante' (Barthes, 2006, p.19).

O signo linguístico é definido pela união não de uma coisa e uma palavra, mas um conceito e uma imagem acústica, ou melhor, um significante e um significado. A imagem acústica não é um som material, uma coisa puramente física, mas a impressão psíquica deixada por este som, registrada com base em nossos sentidos, assim tal imagem é sensorial (Saussure, 2006).

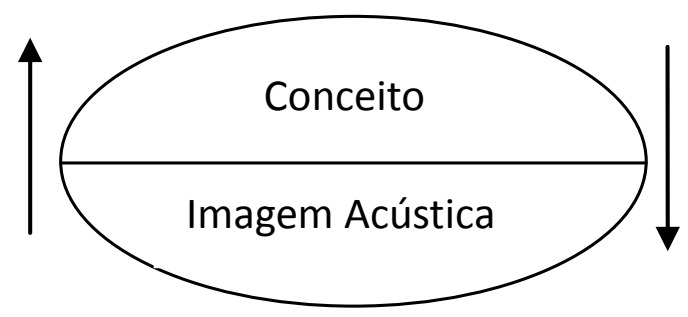

Figura 1. Signo

Fonte: Saussure (2006).

Dessa forma, na concepção de Saussure, o signo é um esquema binário, como uma entidade formada por duas partes. Agora, em outra perspectiva, a semiótica interpretativa, o signo é uma entidade tríade. Segundo Peirce (2008), há um terceiro elemento que denominou de interpretante. O que denota que a relação sígnica deve ser entendida como triádica, e não binária como proposto por Saussure. Portanto, o conceito de signo pela perspectiva de Saussure é formado pela relação entre dois elementos e pela perspectiva de Pierce por três elementos.

Na perspectiva de Peirce, o signo pode ser assim definido:

o processo em que algo funciona como signo pode denominar-se semiosis. (...) este processo implica três (ou quatro) fatores: o que atua como signo, aquele a que o signo alude, e o efeito que produz em determinado interprete em virtude do qual a coisa em questão é um signo para ele (Morris, 1994, p. 27). 
A composição do signo seria assim definida: o veículo sígnico, o designatum e o interpretante (Morris, 1994). De acordo com Eco (2009), a definição de Peirce oferece um algo mais; ela não requer que seja emitida com intenção e produzida de forma artificial, como condição necessária para a definição do signo. A tríade de Peirce pode ainda ser aplicada a fenômenos sem emitente humano, mas que tenha um destinatário necessariamente humano.

A partir dessas conceituações iniciais, pode-se compreender que o campo da semiótica é toda forma de linguagem, em toda a forma de comunicação. Para Santaella (1983, p. 13), "a semiótica é a ciência que tem por objeto de investigação todas as linguagens possíveis, ou seja, que tem por objetivo o exame dos modos de constituição de todo e qualquer fenômeno como fenômeno de produção de significação e de sentido". A importância do estudo da semiótica é dada a partir do pressuposto de que sem informação não há transmissão de mensagem, não permitindo diversas ações subseqüentes, como o planejamento, a reprodução, o processo e o controle (Santaella, 1983). A semiótica é a base da compreensão das principais formas da atividade humana, pois oferece uma linguagem geral, aplicável a qualquer outra forma de comunicação e, consequentemente, aplicável à linguagem de toda e qualquer ciência (Morris, 1994).

Vale esclarecer que, embora tenham algumas semelhanças com a semiótica, o tema "análise do discurso" estabelece outro olhar sobre a comunicação.

A análise do discurso trabalha, tal como a análise de conteúdo, com unidades linguísticas superiores à frase (enunciados).

Mas como o seu objetivo releva da mesma dimensão que o objetivo puramente linguístico do qual ela deriva por extensão - formular as regras de encadeamento das frases, quer dizer, ao fim e ao cabo descrever as unidades (as macro-unidades que são os enunciados) e a sua distribuição - é difícil situá-la na contiguidade (e mesmo no lugar) da análise do conteúdo (Bardin, 2009, p. 46).

Portanto, no caso da análise do discurso, a unidade de análise é o enunciado e, não, o signo em si, como é o caso da Semiótica.

O sentido de relação entre Contabilidade e Semiótica fundamenta-se a partir da perspectiva que se olha a primeira. Nesse sentido, importa rever o entendimento sobre a Contabilidade que possibilita esta relação. A Contabilidade é uma ciência que engloba um conjunto de conhecimentos sistematizados, com princípios e normas próprias. Basicamente, sua função é registrar, classificar, demonstrar, auditar e analisar todas as mutações do patrimônio das organizações, com a finalidade de fornecer informações relevantes aos seus gestores para a tomada de decisões, bem como as demais pessoas com interesses na organização (Franco, 1996). Este fazer contábil obedece a procedimentos específicos que a caracterizam e a definem. Em outras palavras, configura-se por uma linguagem própria, um sistema de códigos, que atenda às particularidades específicas da ciência contábil. Isso ocorre inclusive quando ela utiliza apenas números. Enquanto na linguagem matemática a negatividade do número dois é assim representada "-2", na Contabilidade é por outro signo "(2)". Exemplos como esse podem ilustrar diferenças da linguagem contábil em relação à outra, como também sustenta o entendimento de que a Contabilidade pode ser classificada como uma linguagem.

Hendriksen e Van Breda (1999, p. 29), ao dissertarem sobre o tema, afirmam que "a Contabilidade é uma linguagem. Muitos a consideram como a linguagem dos negócios (...); os números e as classificações contábeis variam no que diz respeito à interpretação que pode ser feita pelo leitor de relatórios contábeis". A Contabilidade, basicamente, utiliza linguagem própria para transmitir os fatos registrados a todos os usuários interessados nessas informações (Anthony, Hawkins \& Merchant, 1975; Ijiri, 1975; Belkaoui, 1995). Ao entender a Contabilidade como linguagem dos negócios, ela poderia estar relacionada com a Semiótica. Uma vez que, como destaca Santaella (1983), a Semiótica é uma ciência que possibilita o estudo sobre todas as linguagens, ela poderia ajudar nos estudos contábeis, entre eles, a relação com os usuários e o sistema normativo, para citar exemplos de orientação de pesquisa. 


\section{Considerações metodológicas}

Esta pesquisa caracteriza-se como bibliográfica, na medida em que analisa artigos publicados nos congressos e nos periódicos internacionais. Ela configurou-se por dois momentos: primeiramente, foram revisadas as publicações em congressos nacionais e a segunda, em revistas científicas internacionais. A Figura 2 apresenta breve caracterização dos congressos.

\begin{tabular}{|ll|}
\hline \multicolumn{1}{|c|}{ Evento } & \multicolumn{1}{c|}{ Características } \\
\hline Congresso Brasileiro de Custos (CBC) & $\begin{array}{l}\text { Principal evento ligado à área de custos empresariais do Brasil. Sua } 1^{\text {a }} \\
\text { edição foi em 1994. }\end{array}$ \\
\hline $\begin{array}{l}\text { Encontro da Associação Nacional de Pós- } \\
\text { Graduação e Pesquisa em Administração }\end{array}$ & $\begin{array}{l}\text { Atualmente é o maior evento brasileiro científico e acadêmico da área de } \\
\text { administração do país. Sua } 1^{\text {a }} \text { edição foi em 1976. }\end{array}$ \\
\hline $\begin{array}{l}\text { Congresso USP de Controladoria e } \\
\text { Contabilidade }\end{array}$ & $\begin{array}{l}\text { Promove o debate de idéias inovadoras sobre a teoria e a prática de } \\
\text { Controladoria e Contabilidade. Sua } 1^{\text {a }} \text { edição ocorreu em 2001. }\end{array}$ \\
\hline
\end{tabular}

Figura 2. Breve caracterização dos Congressos

Fonte: Associação Brasileira de Custos (2009), Associação Nacional de Pós-Graduação e Pesquisa em Administração (2009), e Congresso da USP de Controladoria e Contabilidade (2009).

A coleta de evidências deu-se a partir dos arquivos eletrônicos dos referidos congressos, nos seguintes períodos assim distribuídos: da $1^{\text {a }}$ à $15^{\mathrm{a}}$ edição, de 1994 a 2008, do Congresso Brasileiro de Custos; da 22a à 32a edição, de 1998 a 2008, do Encontro da Associação Nacional de Pós-Graduação e Pesquisa em Administração; e da $1^{\text {a }}$ à $8^{a}$ edição, de 2001 a 2008, do Congresso da USP de Controladoria e Contabilidade. Os arquivos eletrônicos foram obtidos nas respectivas páginas na internet ou em CD-ROM dos congressos. Com relação ao Encontro da Associação Nacional de Pós-Graduação e Pesquisa em Administração (EnAnpad), dada a existência de amplo número de temáticas, mais especificamente à área de Administração, a pesquisa restringiu-se aos artigos da temática Contabilidade, a saber:

- Contabilidade e Controle Gerencial (CCG)

- Finanças e Contabilidade (FIC)

- Contabilidade (COM)

Para os demais congressos, utilizaram-se todas as temáticas, revisando as suas publicações.

Para a seleção dos artigos, foi realizada uma análise deles, com base na identificação de palavras, nos títulos enunciados e em seus respectivos resumos. Foram pesquisadas as seguintes palavras: (1) semiótica; ou (2) análise do discurso. Todos os artigos que possuíam essas palavras foram coletados integralmente e analisados para validação dos que atendiam ao objeto desta pesquisa. Os arquivos válidos selecionados formaram o corpo de análise.

Num segundo momento, foi realizada pesquisa nos periódicos internacionais, a partir da base de referência EBSCOHost, que disponibiliza para consulta a base de dados Business Source Complete. Foram considerados válidos apenas os artigos indexados como científicos pela base de dados, disponíveis com textos completos, com publicação a partir do ano de 1990 e limitados aos principais periódicos específicos da temática contábil (22). A pesquisa foi realizada com os seguintes termos: Semiotic, semiologic, sign, discourse analysis, language theory, nos campos: título, resumo e palavras-chave dos artigos, combinados com os termos accounting, accountancy e book keeping. 


\section{Resultados}

\subsection{Resultados da pesquisa nos eventos brasileiros}

A pesquisa buscou identificar obras que tenham abordado os conhecimentos da Semiótica como instrumento de análise em estudos na área contábil. Assim, foram identificados 7 artigos, todos eles no idioma português, distribuídos em cada congresso, conforme apresentado nas Tabelas de 1 a 3 .

Tabela 1

Publicações Semiótica no Congresso Brasileiro de Custos

\begin{tabular}{cccc}
\hline Ano & Edição & Quantidade de artigos semiótica & Quantidade Total de Artigos \\
\hline 1994 & 1 & 0 & 27 \\
\hline 1995 & 2 & 0 & 88 \\
\hline 1996 & 3 & 0 & 46 \\
\hline 1997 & 4 & 0 & 51 \\
\hline 1998 & 5 & 0 & 79 \\
\hline 1999 & 6 & 0 & 120 \\
\hline 2000 & 7 & 0 & 166 \\
\hline $\mathbf{2 0 0 1}$ & 8 & 1 & 157 \\
\hline $\mathbf{2 0 0 2}$ & 9 & 1 & 183 \\
\hline 2003 & 10 & 0 & 140 \\
\hline 2004 & 11 & 0 & 251 \\
\hline 2005 & 12 & 0 & 350 \\
\hline 2006 & 13 & 0 & 212 \\
\hline 2007 & 14 & 0 & 238 \\
\hline 2008 & 15 & 0 & 259 \\
\hline & & $\mathbf{2}$ & $\mathbf{2 . 3 6 7}$
\end{tabular}

Fonte: Associação Brasileira de Custos (2009).

No Congresso Brasileiro de Custos (Tabela 1), em suas diversas edições, foram encontrados dois artigos que atenderam aos critérios da pesquisa. Eles representam $0,08 \%$ sobre o total de artigos do congresso, considerando as suas 15 edições.

Tabela 2

Publicações Semiótica no Congresso EnAnpad

\begin{tabular}{cccc}
\hline Ano & Edição & Quantidade de Artigos Semiótica & Quantidade Total de Artigos \\
\hline 1998 & 2 & 0 & 12 \\
\hline 1999 & 3 & 0 & 10 \\
\hline 2000 & 4 & 0 & 21 \\
\hline 2001 & 5 & 0 & 23 \\
\hline $\mathbf{2 0 0 2}$ & $\mathbf{6}$ & $\mathbf{1}$ & $\mathbf{4 7}$ \\
\hline 2003 & 7 & 0 & 57 \\
\hline 2004 & 8 & 0 & 70 \\
\hline 2005 & 9 & 0 & 70 \\
\hline 2006 & 10 & 0 & 71 \\
\hline $\mathbf{2 0 0 7}$ & $\mathbf{1 1}$ & $\mathbf{1}$ & $\mathbf{9 4}$ \\
\hline 2008 & 12 & 0 & $\mathbf{7 0}$ \\
\hline & & $\mathbf{2}$ & $\mathbf{5 4 5}$ \\
\hline
\end{tabular}

Fonte: Associação Nacional de Pós-Graduação e Pesquisa em Administração (2009).

No Congresso EnAnpad (Tabela 2), também foram encontrados dois artigos, equivalendo a 0,37\% do total de artigos do congresso, considerando as suas 11 edições. Foram encontrados três artigos que 
atenderam aos critérios da pesquisa, representando $0,37 \%$ do total de artigos das 8 edições do Congresso da USP de Controladoria e Contabilidade (Tabela 3).

Tabela 3

Publicações Semiótica Congresso USP Controladoria e Contabilidade

\begin{tabular}{cccc}
\hline Ano & Edição & Quantidade de Artigos Semiótica & Quantidade Total de Artigos \\
\hline 2001 & 1 & 1 & 74 \\
\hline 2002 & 2 & 0 & 85 \\
\hline 2003 & 3 & 0 & 101 \\
\hline 2004 & 4 & 2 & 100 \\
\hline 2005 & 5 & 0 & 100 \\
\hline 2006 & 6 & 0 & 150 \\
\hline 2007 & 7 & 0 & 120 \\
\hline 2008 & 8 & 0 & 84 \\
\hline & & $\mathbf{3}$ & $\mathbf{8 1 4}$ \\
\hline
\end{tabular}

Fonte: Congresso da USP de Controladoria e Contabilidade (2009).

Percebe-se que, embora seja pequena a participação do tema em relação à quantidade de trabalhos apresentados em todos os congressos, ela sinaliza a emergência desse tipo de estudo. Sua pequena expressividade poderia significar a falta de reconhecimento sobre o potencial de contribuição no desenvolvimento científico da Ciência Contábil. Além disso, o tradicional hermetismo da área e o desconhecimento do instrumento podem ter desestimulado a inserção dessa forma de olhar a Contabilidade.

Na Figura 3, estão apresentados os títulos dos sete artigos encontrados, classificados por congresso, ano e edição.

\begin{tabular}{|cccl|}
\hline Evento & Ano & Edição & \multicolumn{1}{c|}{ Título } \\
\hline CBC & 2001 & 8 & $\begin{array}{l}\text { Um Olhar Fenomenológico sobre a "res" da Logística Contábil na Identificação dos } \\
\text { Custos }\end{array}$ \\
\hline CBC & 2002 & 9 & A Formação do Contador de Custos Ambientais \\
\hline EnAnpad & 2002 & 6 & $\begin{array}{l}\text { Reflexões sobre a Dimensão Semiótica da Análise de Balanços: Uma Contribuição } \\
\text { à Otimização de Decisões de Crédito }\end{array}$ \\
\hline EnAnpad & 2007 & 11 & $\begin{array}{l}\text { Tratamento Contábil dos Projetos de Crédito Carbono no Brasil: Um Estudo } \\
\text { Exploratório }\end{array}$ \\
\hline USP & 2001 & 1 & $\begin{array}{l}\text { A Informação Contábil e a Ordem Social: Uma Contribuição das Teorias } \\
\text { Semióticas e da Comunicação }\end{array}$ \\
\hline USP & 2004 & 4 & $\begin{array}{l}\text { Mensuração da Semiótica na Codificação das Demonstraç̃̃es Contábeis por Meio } \\
\text { de Redes Neurais }\end{array}$ \\
\hline USP & 2004 & 4 & A Responsabilidade Social da Contabilidade para os Estudantes Universitários \\
\hline
\end{tabular}

Figura 3. Títulos dos Artigos

Fonte: Associação Brasileira de Custos (2009), Associação Nacional de Pós-Graduação e Pesquisa em Administração (2009), e Congresso da USP de Controladoria e Contabilidade (2009).

Pelas informações da Figura 3, pode-se verificar a diversidade de assuntos que foram abordados com o uso da semiótica ou da análise do discurso como suporte, não podendo ser destacado qualquer padrão.

Numa análise sobre o conteúdo dos artigos, identificou-se que quatro deles tinham como objetivo destacar o potencial da teoria semiótica como ferramenta de estudo dos assuntos pesquisados/estudados, sugerindo sua utilização. Em outras palavras, não apresentam contribuições de aplicações práticas ou modelos. A aplicação prática foi contemplada em três artigos: dois deles como análise do discurso, um no Congresso EnAnpad e outro no Congresso da USP; e o terceiro como Semiótica, no Congresso da USP. 
A densidade sobre o conteúdo e complexidade no entendimento sobre a semiótica, em suas diferenças, poderia configurar-se como uma barreira, dificultando sua aplicabilidade nos estudos em Ciências Contábeis. Essa dificuldade poderia originar-se também na própria formação do pesquisador, que possui um viés mais quantitativo do que qualitativo. Essas suposições poderiam ser examinadas em estudos mais específicos.

\subsubsection{Os autores dos artigos}

A Tabela 4 apresenta a distribuição dos autores por artigos, como forma de evidenciar a participação deles no desenvolvimento do tema.

Tabela 4

Autores mais presentes nos eventos, por artigo

\begin{tabular}{|c|c|c|c|c|}
\hline Ordem & Autor & $\begin{array}{l}\text { Número de } \\
\text { autorias }\end{array}$ & $\%$ & $\%$ Acum. \\
\hline 1 & Masayuki Nakagawa & 4 & 21,1 & 21,1 \\
\hline 2 & Antônio Manoel R. De Carvalho & 2 & 10,5 & 31,6 \\
\hline 3 & José Maria dias Filho & 2 & 10,5 & 42,1 \\
\hline \multirow[t]{2}{*}{$4-14$} & $\begin{array}{l}\text { Anísio Candido Pereira, Edgard Monforte Merlo, Horacio } \\
\text { Accioly Junior, Ivan Ricardo Peleias, João Bosco Segreti, } \\
\text { Luiz Panhoca, Marcelo Botelho da Costa Moraes, Marcelo } \\
\text { Seido Nagano, Marcelo Theoto Rocha, Nelson Satio Bito e } \\
\text { Olga Maria Panhoca da Silva }\end{array}$ & 1 & 57,9 (5,2/ cada) & 100 \\
\hline & Total & 19 & & \\
\hline
\end{tabular}

Fonte: Associação Brasileira de Custos (2009), Associação Nacional de Pós-Graduação e Pesquisa em Administração (2009), e Congresso da USP de Controladoria e Contabilidade (2009).

Em média, foram 2,7 autores por artigo (Tabela 5). A maior concentração de autores por artigo são duas autorias, encontradas em $42,8 \%$ dos casos (equivalente a três artigos). Os outros quatro artigos possuem em sua autoria um, três, quatro e cinco autores.

Tabela 5

Quantidade de autores por artigo

\begin{tabular}{cccc}
\hline Número de Autores & Frequência & $\%$ & \% Acum. \\
\hline 1 & 1 & 14,2 & 14,2 \\
\hline 2 & 3 & 42,8 & 57,1 \\
\hline 3 & 1 & 14,2 & 71,4 \\
\hline 4 & 1 & 14,2 & 85,7 \\
\hline 5 & 1 & 14,2 & 100,0 \\
\hline Total & $\mathbf{7}$ & & \\
\hline
\end{tabular}

Fonte: Associação Brasileira de Custos (2009), Associação Nacional de Pós-Graduação e Pesquisa em Administração (2009), e Congresso da USP de Controladoria e Contabilidade (2009).

Numa análise mais específica sobre o conteúdo dos artigos, foram identificados 2 artigos, do Congresso da USP, elaborados por um total de nove autores. Nos dois artigos encontrados no EnAnpad, são sete autores e, nos dois artigos encontrados no Congresso $\mathrm{ABC}$, a autoria foi de apenas 3 autores. Agora, vale destacar que o Congresso da $\mathrm{ABC}$ foi o único que não apresentou nenhuma aplicação prática da teoria. 


\subsubsection{Referências}

Não foram computadas as obras sem pertinência ao tema de pesquisa do trabalho. Entretanto, foram consideradas as obras tradicionais de Contabilidade que fornecem suporte a classificação da Contabilidade como uma linguagem.

Tabela 6

Obras mais usadas como referências

\begin{tabular}{|c|c|c|c|c|}
\hline & Obra & Citações & $\%$ & $\%$ Acum \\
\hline 1 & $\begin{array}{l}\text { HENDRIKSEN, Eldon S., BREDA, Michael F. Van. Teoria da Contabilidade. São Paulo: } \\
\text { Atlas, } 1999 .\end{array}$ & 12 & 16,2 & 16,2 \\
\hline 2 & $\begin{array}{l}\text { FINANCIAL ACCOUNTING STANDARDS BOARD. Statement of Financial Accounting } \\
\text { Concepts } n^{\circ} 2 \text {, Qualitative Characteristics of Accounting Information, May } 1980 .\end{array}$ & 7 & 9,4 & 25,6 \\
\hline 3 & $\begin{array}{l}\text { DIAS FILHO, J. M. Características qualitativas da informação contábil: O problema } \\
\text { da compreensibilidade à luz da teoria semiótica e da comunicação. Dissertação de } \\
\text { Mestrado, USP, } 2001 .\end{array}$ & 6 & 8,1 & 33,7 \\
\hline 4 & IUDíCIBUS, Sérgio de. Teoria da Contabilidade. 5 Ed. São Paulo: Atlas, 1997. & 5 & 6,7 & 40,5 \\
\hline 5 & $\begin{array}{l}\text { PRETTO, Clea B.M. E NAKAGAWA, Masayuki. Semiótica e contabilidade: uma } \\
\text { perspectiva interdisciplinar. São Leopoldo - RS } 2000 .\end{array}$ & 3 & 4,0 & 44,5 \\
\hline 6 & $\begin{array}{l}\text { MORRIS, Charles W. Fundamentos da Teoria dos Signos. Rio de Janeiro: Eldorado } \\
\text { Tijuca, } 1976 .\end{array}$ & 2 & 2,7 & 47,3 \\
\hline 7 & SANTAELLA, Lúcia. O que é semiótica. São Paulo: Brasiliense, 1983. & 2 & 2,7 & 50,0 \\
\hline 8 & $\begin{array}{l}\text { MARCHESE, Amauri B. Comunicação: fator estratégico na gestão empresarial. } \\
\text { Revista ESPM, } 2000 .\end{array}$ & 2 & 2,7 & 52,7 \\
\hline 9 & $\begin{array}{l}\text { CARVALHO, Antônio M. R. e NAKAGAWA, Masayuki. Um olhar fenomenológico sobre } \\
\text { a "res" da logística contábil na identificação dos custos. In VII congresso Brasileiro de } \\
\text { Custos - ABCustos Outubro: } 2001 .\end{array}$ & 2 & 2,7 & 55,4 \\
\hline 10 & $\begin{array}{l}\text { ETHERIDGE, Harian Lynn. An examination of Semiotic Theories of Accounting } \\
\text { Accruals. Unpublished Ph.D. Dissertation, Lousiana State University, } 1991 .\end{array}$ & 2 & 2,7 & 58,1 \\
\hline 11 & $\begin{array}{l}\text { BELKAOUI, Ahmed Riahi. The linguistic shaping of accounting. Quorum Books, } \\
\text { Westport, Connecticut: London, } 1995 .\end{array}$ & 2 & 2,7 & 60,8 \\
\hline 12 & $\begin{array}{l}\text { CROPLEY, D. H. Towards formulating a semiotic theory of measurement } \\
\text { information. Measurement, } 1998 .\end{array}$ & 2 & 2,7 & 63,5 \\
\hline 13 & $\begin{array}{l}\text { DUNN. C. L.; GRABSKI, S. V. Perceived semantic expressiveness of accounting } \\
\text { systems and task accuracy effects. International Journal of Accounting Information } \\
\text { Systems. N. 1, p. 79-87, } 2000 \text {. }\end{array}$ & 2 & 2,7 & 66,2 \\
\hline 14 & $\begin{array}{l}\text { PANHOCA, L.; ACCIOLYJR, H.; SILVA, O.M.P.; NAKAGAWA, M. A representação dos } \\
\text { signos “contabilidade, custos e investimento": um enfoque da semiótica. In Anais VIII } \\
\text { Congresso Del Instituto Internacional de Costos. Punta Del Este, Uruguay: Nov. } 2003 .\end{array}$ & 2 & 2,7 & 68,9 \\
\hline 15 & $\begin{array}{l}\text { REINERT, M. Alceste, une méthodologie d'analyse des données textuelles et une } \\
\text { application. Bulletin de méthodologie sociologique, (28) p. 24-54, } 1996 .\end{array}$ & 2 & 2,7 & 71,6 \\
\hline 16 & $\begin{array}{l}\text { NAKAGAWA, Masayuki; PRETTO, Clea Beatriz Macagnan. An interdisciplinary view } \\
\text { of accountancy in Brazil, In: Asian-Pacific Conference on International Accounting } \\
\text { Issues, 12th. Anais. China, } 2000\end{array}$ & 2 & 2,7 & 74,3 \\
\hline \multirow[t]{2}{*}{17} & MOST, K.S. Accounting Theory. 2a ed. Columbus, Ohio: Grid, 1982. & 2 & 2,7 & 77,0 \\
\hline & Total & 57 & & \\
\hline
\end{tabular}

Fonte: Associação Brasileira de Custos (2009), Associação Nacional de Pós-Graduação e Pesquisa em Administração (2009).

e Congresso da USP de Controladoria e Contabilidade (2009).

Os dados foram obtidos depois de uma equalização das referências, respeitando-se a edição e o ano das obras, em razão da diversidade de formas de referenciação. Outro aspecto importante do tratamento dos dados é que não foram consideradas aquelas referências listadas, mas não citadas no texto dos artigos, porque se entendeu que elas não foram utilizadas no trabalho. A obra mais citada, considerando-se todos os artigos, é o livro Teoria da Contabilidade, de autoria de Eldon S. Hendriksen e Michael 
F. Van Breda, com doze citações. Em segundo lugar, aparece a norma n. 2 do FASB. Em terceiro lugar, com seis citações, aparece a dissertação de mestrado de José Maria Dias Filho, intitulada "Características qualitativas da informação contábil: o problema da compreensibilidade à luz da teoria da semiótica e da comunicação". O quarto lugar é ocupado pelo livro Teoria da Contabilidade, de Sérgio de Iudícibus. Em quinto lugar, aparece o artigo "Semiótica e contabilidade: uma perspectiva interdisciplinar", de Pretto e Nakagawa (2000). Somente em sexto lugar, aparece o livro Fundamentos da Teoria dos Signos, de Charles W. Morris, a primeira obra da relação que trata especificamente do assunto Semiótica.

Várias referências sobre teoria contábil usadas nos textos, entre as quais diversas das clássicas, sustentam tratar a Contabilidade como a linguagem dos negócios. Uma vez que ela pode ser assim considerada, passa a ser objeto de estudo da Semiótica.

Na soma de todos os artigos, ocorreram 74 citações. Destas, 57 estão listadas na Tabela 6, o que corresponde a $77 \%$ das citações feitas. Pelo perfil dessas obras, nota-se uma falta de referências a obras mais consistentes e robustas que tratem especificamente do tema Semiótica. Em geral, os trabalhos apresentaram uma bibliografia incipiente sobre o tema.

\subsubsection{Autores}

A Tabela 7 mostra a distribuição da citação a autores nos artigos, como forma de evidenciar a participação e relevância deles no desenvolvimento do tema. Na soma de todos os artigos, foram encontradas 97 citações a autores. As 58 listadas na Tabela 7 representam 59,7\% do total. Pode-se inferir que faltam autores conceituados e pilares sobre a teoria Semiótica. O único autor com foco semiótico específico e com três citações ou mais é Lúcia Santaella. Observou-se que, na grande parte dos artigos, o que ocorre é um reforço às principais ideias dos autores consultados e, não, novas contribuições teóricas ou práticas que deem continuidade ao aperfeiçoamento do tema.

Tabela 7

Citações de autores

\begin{tabular}{|c|c|c|c|c|}
\hline & Referência - Autor & Número de citações & $\%$ & $\%$ Acum. \\
\hline 1 & HENDRIKSEN, E.S. & 12 & 12,3 & 12,3 \\
\hline 2 & VAN BREDA, M.F. & 12 & 12,3 & 24,7 \\
\hline 3 & NAKAGAWA, M. & 10 & 10,3 & 35,0 \\
\hline 4 & DIAS FILHO, J.M. & 7 & 7,2 & 42,2 \\
\hline 5 & IUDÍCIBUS, S. & 6 & 6,1 & 48,4 \\
\hline 6 & PRETTO, C.B.M. & 5 & 5,1 & 53,6 \\
\hline 6 & PRETTO, C.B.M. & 5 & 5,1 & 53,6 \\
\hline 7 & BELKALUI, A.R. & 3 & 3,0 & 56,7 \\
\hline \multirow[t]{2}{*}{8} & SANTAELLA, L. & 3 & 3,0 & 59,7 \\
\hline & Total & 58 & & \\
\hline
\end{tabular}

Fonte: Associação Brasileira de Custos (2009), Associação Nacional de Pós-Graduação e Pesquisa em Administração (2009), e Congresso da USP de Controladoria e Contabilidade (2009).

\subsection{Resultados da pesquisa nos periódicos internacionais}

Primeiramente, foi realizada uma análise sobre a abordagem da semiótica nos periódicos internacionais disponíveis na base de referências EBSCOHost nas áreas de Administração, Economia e Contabilidade, como pode ser verificado na Tabela 8. Nesta análise, foram considerados apenas os artigos científicos, ou seja, outros tipos de literatura foram descartados. 
A presença do termo semiotic no título dos artigos seria uma evidência do uso desta teoria. Essa pesquisa foi uma forma de mostrar a abordagem dada à teoria nos periódicos nas respectivas áreas das ciências sociais. Pode-se notar que os periódicos direcionados à administração possuem uma abordagem mais significativa do tema, sendo encontrados dez artigos. Já na área da Economia, foram encontrados apenas quatro artigos. Nos periódicos direcionados à Contabilidade, não foi encontrado nenhum artigo que atendeu ao critério utilizado, indicando um desinteresse pelo tema.

Tabela 8

Abordagem da Semiótica na Administração, Economia e Contabilidade

\begin{tabular}{ccc} 
& No título da publicação & Quantidade de Artigos \\
\hline $1^{\text {a }}$ & Managenent & 10 \\
\hline $2^{\text {a }}$ & Economic & 4 \\
\hline $3^{\text {a }}$ & Accounting & 0 \\
\hline & Total & $\mathbf{1 4}$ \\
\hline
\end{tabular}

Fonte: EBSCOHost (2009).

Em seguida, utilizando a mesma base de referências, foi realizada uma análise de 22 periódicos internacionais específicos da área de Contabilidade. A presença de um dos termos (semiotic, semiologic, sign, discourse analysis, language theory em um dos campos - título, resumo e palavras-chave dos artigos, combinados com os termos accounting, accountancy e book keeping) foi considerada uma evidência do uso desta teoria. Nessa análise, foram considerados apenas os artigos científicos, ou seja, outros tipos de literatura foram descartados. O período analisado variou segundo a disponibilidade do periódico oferecida pela base de dados, entre os anos de 1990 e 2009.

\begin{tabular}{|c|c|c|c|c|c|c|c|c|c|c|c|c|c|c|c|c|c|c|c|c|c|}
\hline & Periódico/Ano Publicação & 90 & 1 & 2 & 3 & 4 & 5 & 6 & 7 & 8 & 9 & 00 & 1 & 2 & 3 & 4 & 5 & 6 & 7 & 8 & 9 \\
\hline 1 & Abacus & & & & & & & & & & & & & & & & & & & & \\
\hline 2 & Accountancy & & & & & & & & & & & & & & & & & & & & \\
\hline 3 & Accountancy: International Edition & & & & & & & & & & & & & & & & & & & & \\
\hline 4 & Accounting \& Business Research & & & & & & & & & & & & & & & & & & & & \\
\hline 5 & Accounting Review & & & & & & & & & & & & & & & & & & & & \\
\hline 6 & Accounting, Auditing \& Accountability Journal & & & & & & & & & & & & & 1 & & & & & 3 & & 1 \\
\hline 7 & Accounting, Organizations and Society & & & & & & & & & & & 1 & & & & & & & & & \\
\hline 8 & Applied Economics & & & & & & & & & & & & & & & & & & & & \\
\hline 9 & British Accounting Review & & & & & & & & & & & & & & & & & & & & \\
\hline 10 & European Accounting Review & & & & & & & & & & & & & & & & & & & & \\
\hline 11 & International Journal of Accounting & & & & & & & & & & & & & & & & & & & & \\
\hline 12 & International Money Marketing & & & & & & & & & & & & & & & & & & & & \\
\hline 13 & Journal Accounting \& Economics & & & & & & & & & & & & & & & & & & & & \\
\hline 14 & Journal of Accounting \& Public Policy & & & & & & & & & & & & & & & & & & & & \\
\hline 15 & Journal of Accounting Research & & & & & & & & & & & & & & & & & & & & \\
\hline 16 & Journal of Business & & & & & & & & & & & & & & & & & & & & \\
\hline 17 & Journal of Business Finance \& Accounting & & & & & & & & & & & & & & & & & & & & \\
\hline 18 & Journal of Finance & & & & & & & & & & & & & & & & & & & & \\
\hline 19 & Journal of Financial Services Research & & & & & & & & & & & & & & & & & & & & \\
\hline 20 & Journal of International Business Studies & & & & & & & & & & & & & & & & & & & & \\
\hline 21 & Journal of Int. Financial Manag. \& Accounting & & & & & & & & & & & & & & & & & & & & \\
\hline 22 & Review of Quantitative Finance \& Accounting & & & & & & & & & & & & & & & & & & & & \\
\hline
\end{tabular}

Figura 4. Periódicos internacionais analisados

Fonte: EBSCOHost (2009). 
Pode-se perceber uma concentração de publicações de trabalhos, abordando o tema de pesquisa no Accounting, Auditing \& Accountability Journal. Este periódico parece reconhecer a relevância do tema ao incluí-lo mais de uma vez em suas publicações. Além dos artigos encontrados neste periódico, foi encontrado mais um artigo, na Accounting, Organization and Society. Portanto, não foi encontrado nenhum outro artigo nos demais periódicos, nas publicações oferecidas ao longo de 20 anos revisados. O que ratifica o resultado obtido com a análise dos congressos nacionais e evidenciando que há pouquíssimos trabalhos efetuados que combinam a Semiótica com a Contabilidade. Pesquisas mais específicas poderiam trazer à luz as razões dessa pouca exploração sobre o tema.

Uma análise mais aprofundada dos artigos encontrados pode ser visualizada na Figura 5, em que se encontram listados todos os autores, ano de publicação e descrição da pesquisa. Dos seis artigos encontrados, quatro utilizam a análise do discurso e apenas dois abordam a Semiótica. Há pouca quantidade de artigos encontrados nas referências internacionais, o que comprova que há pouca pesquisa contábil instrumentalizada pela teoria da Semiótica.

\begin{tabular}{|lll|}
\hline \multicolumn{1}{|c|}{ Autores } & $\begin{array}{c}\text { Ano } \\
\text { Publ }\end{array}$ & \multicolumn{1}{c|}{ Descrição da Pesquisa } \\
\hline $\begin{array}{l}\text { Macintosh; Shearer; } \\
\text { Thornton; Welker* }\end{array}$ & 2000 & $\begin{array}{l}\text { O estudo investiga o estado ontológico da informação dos relatórios contábeis } \\
\text { através de duas vertentes independentes: Ordens de Simulacro de Baudrillard e a } \\
\text { Teoria da Contabilidade Financeira. }\end{array}$ \\
\hline Macintosh; Baker** & 2002 & $\begin{array}{l}\text { O estudo adotou uma perspectiva de teoria literária para descrever os relatórios } \\
\text { contábeis e informações como textos, ao invés de mercadorias econômicas, e assim } \\
\text { disponível para análise sob o ponto de vista da teoria linguística da Semiótica. }\end{array}$ \\
\hline Ferguson** & 2007 & $\begin{array}{l}\text { Objetiva destacar a abordagem tríplice de John B. Thompson como uma metodologia } \\
\text { útil para resolver deficiências em estudos existentes sobre Contabilidade com } \\
\text { proposta de analisar os "textos" contábeis. }\end{array}$ \\
\hline Haslam; Roper** & 2007 & $\begin{array}{l}\text { O propósito deste artigo é prover uma resposta ao artigo Analysing accounting } \\
\text { discourse: avoiding the "fallacy of internalism", de Ferguson. }\end{array}$ \\
\hline Llewellyn; Milne** & 2007 & $\begin{array}{l}\text { O objetivo do trabalho é introduzir a questão da codificação na Contabilidade como } \\
\text { um discurso, explicar a ideia de codificação e localizar a noção de um discurso } \\
\text { codificado. Considerando a relação entre o discurso codificado e a prática pode } \\
\text { adicionar à compreensão geral do discurso/prática nos estudos organizacionais. }\end{array}$ \\
\hline Hudaib; Haniffa** & 2009 & $\begin{array}{l}\text { Explorar a construção dos significados para os auditores independentes, num estado } \\
\text { autocrático rico em petróleo. }\end{array}$ \\
\hline
\end{tabular}

Figura 5. Autores, Ano e Descrição da Pesquisa

* Accounting Organizations and Society;

** Accounting, Auditing \& Accountability Journal.

Fuente: EBSCOHost (2009)

Na Figura 6, são apresentados os resultados de cada artigo. Outro aspecto evidenciado por esta segunda parte da pesquisa é a difusão de temas contábeis nos quais a teoria é aplicada, o que comprova a flexibilidade da Semiótica para tratar dos mais diversos temas presente nas diversas ciências que se apoiam na linguagem para transmitir informações. 


\begin{tabular}{|c|c|c|}
\hline Autores & $\begin{array}{l}\text { Ano } \\
\text { Publ }\end{array}$ & Resultados da Pesquisa \\
\hline $\begin{array}{l}\text { Macintosh; Shearer; } \\
\text { Thornton; Welker* }\end{array}$ & 2000 & $\begin{array}{l}\text { Conclui que a atual Contabilidade não se refere mais a qualquer realidade objetiva, } \\
\text { mas em vez disso circunda uma "hiper-realidade" de modelos autorreferenciais. }\end{array}$ \\
\hline Macintosh; Baker** & 2002 & $\begin{array}{l}\text { Concluiu destacando uma nova forma de preparação de relatórios contábeis } \\
\text { baseado na noção heteroglossica de Mikhail Bakhtin. }\end{array}$ \\
\hline Ferguson** & 2007 & $\begin{array}{l}\text { Conclui que Gallhofer et al. faz inferências sobre a produção de cartas sem } \\
\text { considerar nenhuma análise formal de produção ou recepção, ou sem prestar } \\
\text { atenção suficiente ao contexto social e histórico. }\end{array}$ \\
\hline Haslam; Roper** & 2007 & $\begin{array}{l}\text { O texto defende Gallhofer et al. em sua escolha para promover a análise crítica do } \\
\text { discurso respeitando o foco da Contabilidade e finanças. }\end{array}$ \\
\hline Llewellyn; Milne** & 2007 & Identifica alguns tópicos que necessitam de futuras investigações empíricas. \\
\hline Hudaib; Haniffa** & 2009 & $\begin{array}{l}\text { Através da análise do discurso, o estudo mostra que essa construção é feita na } \\
\text { aparência e na realidade através de interações sociais classificadas em três tipos: } \\
\text { micro, meso e macro. }\end{array}$ \\
\hline
\end{tabular}

Figura 6. Autores, Ano e Resultados da Pesquisa

* Accounting Organizations and Society;

** Accounting, Auditing \& Accountability Journal.

Fuente: EBSCOHost (2009).

Partindo do pressuposto de que Contabilidade pode ser entendida como linguagem de negócios (Hendriksen; Van Breda, 1999; Anthony et al., 1975; Ijiri, 1975; Belkaoui, 1995), a comunicação organizacional seria estabelecida com base na mesma linguagem. A tomada de decisão por parte dos gestores estaria mediada por signos que a definem. A riqueza desta comunicação estaria relacionada com a qualidade dos textos produzidos pela Contabilidade.

O desenvolvimento da pesquisa em Contabilidade e Administração, utilizando evidências quantitativas e considerando as publicações nacionais e internacionais, tem se valido de técnicas estatísticas que oportunizam estabelecer um nível explicativo. Se observarmos o desenvolvimento da pesquisa com evidências qualitativas, a situação é outra, pois no máximo o nível atingido é exploratório ou descritivo. Nesse contexto, a Semiótica, reconhecida como ciência dos signos ou teoria das linguagens, poderia contribuir para o desenvolvimento de pesquisas que analisam evidências qualitativas com maior robustez. A teoria Semiótica tem oportunizado avanços na pesquisa em áreas de conhecimento, como Medicina, Comunicação, Direito, entre outras. Para a Contabilidade, a Semiótica poderia contribuir para uma análise crítica da escrita contábil, oportunizando reflexões que venham a trazer um novo papel aos profissionais da área contábil. Esses profissionais enfrentam o desafio de oferecer algo mais do que a tecnologia oportuniza em termos de produtos contábeis, possibilitando uma tomada de decisão mais eficiente por parte dos gestores ou dos stakeholders.

O pequeno número de estudos que consideram o estudo da semiótica, quando vistos a Tabela $8 \mathrm{e}$ a Figura 4, mostra a pouca importância dada pela Ciência Contábil a essa temática. Tal conduta pode indicar que a influência da informação contábil sobre o usuário, seja ele externo ou interno, não tem sido prioridade, pelo menos de pesquisa, na área. Isso contradiz frontalmente os autores consultados que assinalam que o papel da Contabilidade é de fornecer informações relevantes aos seus usuários (Franco, 1996).

\section{Conclusões}

Pode-se constatar que a base teórica da Semiótica em relação ao seu uso na Contabilidade é ainda incipiente. Não há no Brasil um número significativo de estudos na Contabilidade sob o foco da Semiótica, tendo em vista os poucos artigos encontrados nos congressos pesquisados.

Igualmente, foi constatado que, internacionalmente, o tema possui poucos estudos publicados nos 
periódicos revisados. Numa comparação dos estudos em Contabilidade com os de Administração e Economia, observa-se que (apesar de também ser reduzida) há uma menor quantidade de publicações sob o foco da Semiótica em Contabilidade. Na pesquisa internacional, com exceção de duas revistas, não foram encontrados trabalhos em nenhuma outra publicação na área da Ciência Contábil, o que evidencia que também em nível internacional falta ênfase sob o tema.

Outro aspecto relevante verificado nos artigos dos congressos nacionais é que faltam nesses artigos referências e pesquisas em obras mais consistentes e robustas que tratem do tema Semiótica. De fato, autores clássicos, como Charles Sanders Peirce, Ferdinand Saussure, Louis Hjelmslev, Claude Lévi-Strauss, Algirras J. Greimas, Thomas A. Sebeok, Jean Baudrillard, Winfried Nöth, Charles Morris, Umberto Eco e Roland Barthes, praticamente não são citados, o que refletiu em referências teóricas sobre Semiótica de forma frágil na quase totalidade dos trabalhos.

O tema Semiótica revela-se bastante complexo, com vários artigos tentando abranger muitas soluções e tratando a Semiótica como panaceia para os problemas de comunicação da Contabilidade. Não há, necessariamente, uma garantia de que a aplicação da Semiótica resolva problemas, como, por exemplo, o da compreensão por parte do leitor. Sua utilidade poderia estar muito mais voltada a uma técnica de análise do que a uma solução para o problema.

O estudo teve como limitações a pesquisa em três congressos nacionais, já que outros congressos podem ter abordado o tema e não foram considerados pelo presente trabalho. Da mesma forma, a pesquisa não se estendeu às revistas científicas nacionais e aos congressos internacionais. Na busca pelos artigos, a pesquisa limitou-se às opções de procura disponibilizadas pelos sites dos congressos e pelas bases de dados utilizadas no EBSCOHost, aspecto que justifica a necessidade de diferenciação nos procedimentos de coleta dos artigos entre os congressos e as revistas.

A falta de estudos que utilizam a abordagem da Semiótica na Contabilidade abre muitos espaços para novos trabalhos que aproveitem o potencial dessa teoria nas ciências que necessitam apoiar-se na comunicação para promover a eficácia de suas ações. Nesses trabalhos, poderiam enquadrar-se os mais diversos subtemas contábeis.

\section{Referências}

Associação Brasileira de Custos. (2009). Congressos. Recuperado em 20 julho, 2009 de http://www.abcustos. org.br/congressos

Associação Nacional de Pós-Graduação e Pesquisa em Administração. (2009). Eventos. Recuperado em 05 agosto, 2009 de http://anpad.org.br/eventos.php

Anthony, R. N., Hawkins, D. \& Merchant, K. (1975). Accounting: text and cases. Chicago: Irwin.

Bardin, L. (2009). Análise de Conteúdo (4a ed., L. A. Reto e A. Pinheiro, Trad.). Lisboa: Edições 70.

Barthes, R. (2006). Elementos de Semiologia (16a ed., I. Blikstein, Trad.). São Paulo: Cultrix.

Belkaoui, Ahmed R. (1995). The linguistic shaping of accounting. London: Quorum Books.

Coelho Netto, J. T. (1990). Semiótica, Informação e Comunicação (3a ed.). São Paulo: Perspectiva.

Collis, J., \& Hussey, R. (2005). Pesquisa em Administração: um guia prático para alunos de graduação e pós-graduação. (2a ed., L. Simonini. Trad.). Porto Alegre: Bookman.

EBSCOHost. Recuperado em 15 dezembro, 2009 de http://web.ebscohost.com/ehost/

Eco, U. (2009). Tratado Geral de Semiótica. (4a ed. A. de P. Danesi e G. C. C. de Souza, Trad.). São Paulo: Perspectiva.

Ferguson, J. (2007). Analysing accounting discourse avoiding the "fallacy of internalism". Accounting, Auditing \& Accountability Journal, 20(6), 912-934. 
Franco, H. (1996). Contabilidade Geral (23a ed.). São Paulo: Atlas.

Gallhofer, S., \& Haslan, J. (2007). Reply to: "Analysing accounting discourse: avoiding the 'fallacy of internalism"'. Accounting, Auditing \& Accountability Journal, 20(6), 935-940.

Hendriksen, E. S., \& Van Breda, M. F. (1999). Teoria da Contabilidade. (5a ed., A. Z. Sanvicente, Trad.), São Paulo: Atlas.

Hudaib, M., \& Haniffa, R. (2009). Exploring auditor independence: an interpretive approach. Accounting, Auditing \& Accountability Journal, 22(2), 221-246.

Ijiri, Y. (1975). Theory of accounting measurement. Sarasota: American Accounting Association.

Llewellyn, S., \& Milne, M. L. (2007). Accounting as codified discourse. Accounting, Auditing \& Accountability Journal, 20(6), 805-824.

Macintosh, N. B., \& Baker, C. R. (2002). A literary theory perspective on accounting: Towards heteroglossic accounting reports. Accounting, Auditing \& Accountability Journal, 15(2), 184-222.

Macintosh, N. B., Shearer, T., Thornton, D. B., \& Welker, M. (2000). Accounting as simulacrum and hyperreality: perspectives on income and capital. Accounting Organizations and Society, 25(1), 13-50.

Morris, C. (1976). Fundamentos da Teoria dos Signos (1a ed.). São Paulo: Universidade de São Paulo.

Morris, C. (1994). Fundamentos de la Teoria de los Signos (2a ed.). Barcelona: Ediciones Paidós Ibérica.

Nöth, W. (1995). Panorama da Semiótica: de Platão a Peirce. São Paulo: Annablume.

Peirce, C. S. (2008). Semiótica (4a ed., J. T. Coelho Neto, Trad.). São Paulo: Perspectiva.

Pretto, C. B. M. (1999). Una vision interdisciplinary de comunicación: semiótica y negociación. Revista Latina de Comunicación Social: La Laguna, (13).

Santaella, L. (1983). O que é Semiótica (1a ed.). São Paulo: Editora Brasiliense.

Saussure, F. (2006). Curso de Linguística Geral (27a ed., A. Chelini, Trad.). São Paulo: Cultrix.

Universidade de São Paulo. (2009). Congresso USP de Contabilidade e Controladoria: Congressos. Recuperado em10 julho, 2009 de http://www.congressousp.fipecafi.org

Volli, U. (2004). Semiotica della pubblicità. Roma: Laterza.

Watzlawick, P., Beavin, J. H., \& Jackson, D. D. (1971). Pragmatica della comunicazione umana. Roma: Astrolabio. 